\title{
The combination of high bacterial count and positive biofilm formation is associated with the inflammation of pressure ulcers
}

This article was published in the following Dove Press journal:

Chronic Wound Care Management and Research

\author{
Mao Kunimitsu' \\ Gojiro Nakagami ${ }^{1,2}$ \\ Aya Kitamura' \\ Yuko Mugita' \\ Kaname Akamata ${ }^{3}$ \\ Sanae Sasaki ${ }^{4}$ \\ Chieko Hayashi ${ }^{4}$ \\ Yukie Mori' \\ Hiromi Sanada ${ }^{1,2}$ \\ 'Department of Gerontological \\ Nursing/Wound Care Management, \\ Graduate School of Medicine, The \\ University of Tokyo, Tokyo, Japan; \\ ${ }^{2}$ Global Nursing Research Center, \\ Graduate School of Medicine, The \\ University of Tokyo, Tokyo, Japan; \\ ${ }^{3}$ Department of Dermatology, The \\ University of Tokyo Hospital, Tokyo, \\ Japan; ${ }^{4}$ Department of Nursing, The \\ University of Tokyo Hospital, Tokyo, \\ Japan
}

Correspondence: Hiromi Sanada The University of Tokyo, Faculty of Medicine Building 5-307, 7-3-I, Hongo, Bunkyo-ku, Tokyo II 3-0033, Japan Tel/Fax +8I 35 84I 34I9

Email hsanada-tky@umin.ac.jp
Objective: Evaluating the bacterial bioburden of pressure ulcers through bacterial count and pathogenicity is important but is currently difficult to perform in the clinical setting. In order to address this problem, we proposed two methods: 1) measurement of bacterial count using a quantitative device and 2) detection of biofilm formation by wound blotting. The purpose of this study was to investigate the relationship between the bacterial bioburden, assessed by combining these two methods, and the presence of wound inflammation.

Patients and methods: The participants of this cross-sectional study were patients aged $>20$ years with category II, III, IV, or unstageable pressure ulcers examined during a routine round in an interdisciplinary pressure ulcer team between July 2014 and April 2018. Relevant clinical information, including bacterial count, biofilm formation, and presence of inflammation, was collected from the pressure ulcer round record. The relationship between the bacterial bioburden and the presence of inflammation was analyzed using multilevel logistic regression analysis.

Results: We included 273 samples obtained from 98 patients. High bacterial count was significantly associated with wound inflammation $(P=0.009)$ and positive biofilm formation tended to be associated with wound inflammation $(P=0.076)$. In terms of combining these parameters, high bacterial count and positive biofilm formation were significantly associated with wound inflammation (OR: 4.61, 95\% CI: 1.37-15.46, $P=0.013$ ).

Conclusion: Assessment using both bacterial count and biofilm detection parameters may provide more accurate evaluation of the bacterial bioburden of the wound and contribute to appropriate wound care.

Keywords: wound infection, wound assessment, critical colonization, wound blotting, thermography

\section{Introduction}

Excessive inflammation in wounds contributes to delayed healing. The immune response against bacteria that invade the wound tissue is attributed in part to wound inflammation. Pressure ulcers are continuously exposed to exogeneous opportunistic pathogens by commensal skin bacteria or stool. In addition, many patients with pressure ulcers have weakened immune systems, which puts them at high risk for wound infection. Khor et al reported that the presence of an infected deep pressure ulcer is an independent predictor of mortality in pressure ulcer patients that are at least 65 years old (HR: 2.21). ${ }^{1}$ The presence of infected pressure ulcers increases the risk of bacteremia by seven times in pressure ulcer patients and elevates the risk of death by 30 times in patients with bacteremia. ${ }^{2}$ Accordingly, the assessment of bacterial bioburden in daily care is important, and health care workers should work to prevent the development of 
pressure ulcer infection. Bacterial bioburden can be defined by two aspects: bacterial count and pathogenicity. The culture method is widely used in the clinical setting for quantifying bacterial count. ${ }^{3}$ Although wound biopsy is the gold standard for diagnosing wound infection, it is considered to be overly invasive and time-consuming. The presence of viable but nonculturable bacteria has become a problem in the identification of bacteria using the culture method. It has been reported that anaerobic bacteria are present in chronic wounds, ${ }^{4}$ but are difficult to collect, leading to underestimated results. ${ }^{5,6}$ To overcome this, we utilized a culture-independent quantitative device. The Bacteria Counter measures the total number of bacterial cells collected by a sterile swab from a wound surface by measuring the dielectrophoretic impedance of the sample. ${ }^{7}$ By comparing the bacterial counts before and after washing, this quantitative method can be used as an assessment tool for wound cleansing techniques. ${ }^{8}$ Additionally, the reliability of the device for measuring bacterial counts in pressure ulcer sites has already been confirmed. ${ }^{9}$ In conclusion, the noninvasive and convenient nature of the Bacteria Counter means that bacterial count measurements can now be performed at bedside to assess bacterial bioburden.

Biofilm-based wound care has recently attracted attention, ${ }^{10}$ and guidelines now recommend debridement and topical antiseptics for biofilms on the wound surface. ${ }^{3}$ Biofilms are usually identified by observing the bacteria and polysaccharides in the wound tissue by microscopy. However, this method involves wound biopsy, an invasive procedure, and is not preferable for bedside observation of wounds. Therefore, we proposed the noninvasive and simple wound blotting method for biofilm detection. ${ }^{11}$ In this method, polysaccharides in the exudate are collected by attaching a nitrocellulose membrane to the wound surface, and biofilms are visualized by staining with either ruthenium red or alcian blue. We reported that this method can predict the increased slough formation in pressure ulcers. ${ }^{11}$ Thus, using this method along with the Bacteria Counter allows clinicians to evaluate both quantity and quality of bacterial bioburden noninvasively at bedside. However, how the assessment of bacterial bioburden by combining bacterial count and pathogenicity relates to wound inflammation has not yet been clarified. In the present study, we evaluate the relationship between bacterial bioburden and the presence of wound inflammation.

\section{Patients and methods}

\section{Study design and participants}

This cross-sectional study was conducted at a university hospital in an urban area of Tokyo, Japan. The participants were patients aged $\geq 20$ years and were examined during a routine round in an interdisciplinary pressure ulcer team between July 2014 and April 2018. The inclusion criterion was the presence of category II, III, IV, or unstageable pressure ulcers according to the international National Pressure Ulcer Advisory Panel, European Pressure Ulcer Advisory Panel and Pan Pacific Pressure Injury Alliance pressure ulcer classification system. ${ }^{3}$ We excluded the pressure ulcer samples that did not receive thermal imaging assessment, measurement of bacterial count, and biofilm detection. The samples whose surfaces were covered completely with hard and/or thick necrotic tissue were also excluded because inflammation could not be evaluated accurately for these samples. $^{12}$

\section{Bacterial count system}

The rapid bacteria quantification system (Bacteria Counter, DU-AA01NP-H; Panasonic Healthcare Co. Ltd., Tokyo, Japan) was used for measuring bacterial count. ${ }^{7}$ This device displays data ranging from $1.0 \times 10^{5}$ colony forming unit (CFU) $/ \mathrm{mL}$ to $1.0 \times 10^{8} \mathrm{CFU} / \mathrm{mL}$. The researcher swabbed the longest axis of the pressure ulcer once using a cotton-tipped sterilized swab. The collected swab was transferred to a normal saline bottle, which acted as an accessory to the Bacteria Counter. ${ }^{8,9}$ The bacterial count per swab was measured at bedside within 60 seconds. In the present study, we measured the bacterial counts before wound cleansing to evaluate the bacterial bioburden at the wound surface. Bacterial counts greater than $1.0 \times 10^{7} \mathrm{CFU} / \mathrm{mL}$ were considered high.

\section{Wound blotting}

In this study, we collected wound blotting samples before wound cleansing and debridement to detect for biofilm formation. A nitrocellulose membrane (Bio-Rad Laboratories Inc., Hercules, CA, USA) was firmly pressed to the wound bed for 10 seconds. The membranes absorbing the exudate were stored at $4^{\circ} \mathrm{C}$ until staining. Membranes were stained using either ruthenium red or alcian blue. ${ }^{11}$ Ruthenium red staining was performed as follows: each nitrocellulose membrane was premoistened with distilled water, stained with $5 \mathrm{mg} / \mathrm{mL}$ ruthenium red solution (Wako Pure Chemical Industries, Ltd., Osaka, Japan) for 2 minutes, washed with distilled water, and destained thrice with $10 \%$ acetic acid $/ 40 \%$ methanol solution for 30 minutes. Alcian blue staining was performed as follows: each nitrocellulose membrane was soaked into the first cation detergent solution (Saraya Co. Ltd., Osaka, Japan) for 30 seconds with shaking, stained with alcian blue solution (Saraya Co. Ltd.) for 30 seconds, and then soaked in the second cation detergent solution for 60 
seconds with shaking. Positive or negative biofilm formation was evaluated by the observation of signal on the nitrocellulose membrane. We did not consider the signal to be positive when only the part corresponding to the wound edge was stained as exudate likely accumulated in that area.

\section{Thermographic assessment}

We used thermographic assessment for detecting the presence of latent inflammation. ${ }^{12}$ Thermographic images of the wound bed and periwound skin were captured using infrared thermography to assess wound bed temperature (CPA-T400A; FLIR Systems, Inc., Wilsonville, OR, USA). We obtained the images before wound cleansing because the temperature of skin and wound bed after cleansing would be affected by evaporation. Pressure ulcers with a higher temperature in the wound bed than in the periwound skin were determined to be positive for inflammation. ${ }^{12}$

\section{Data collection}

Data, including the patients' demographic characteristics (age and sex) and pressure ulcer location, were collected from the patients' medical records. Relevant clinical information, including the treatment (debridement, antibiotic, and silicone foam dressing), pressure ulcer severity (DESIGN-R ${ }^{\circledR}$ ), bacterial count (Bacteria Counter), biofilm formation (wound blotting), and inflammation (thermography) were collected from the pressure ulcer round records. DESIGN-R ${ }^{\circledR}$ is a wound assessment tool for evaluating the severity of pressure ulcers and monitoring the wound healing process using seven parameters: depth (pressure ulcer severity category; d2, D3, D4, D5, and DU which means unstageable pressure ulcers because its depth is impossible to be measured), amount of exudate, size (width $\times$ length), inflammation/infection, granulation tissue (percentage of healthy granulation tissue relative to the whole wound area), necrotic tissue (presence of soft or hard necrotic tissue), and undermining. Higher DESIGN-R ${ }^{\circledR}$ scores represent higher pressure ulcer severity. ${ }^{13,14}$

\section{Statistical analysis}

Values are presented as the mean with SD. The chi-squared test was used to compare the high and low bacterial counts, and the positive and negative biofilm formation parameters, respectively. Since there are multicollinearities between bacterial counts and biofilm formation, a composite variable for bacterial bioburden was created by combining bacterial count and biofilm formation, thus categorizing wounds as follows: negative biofilm formation, low bacterial count and positive biofilm formation, or high bacterial count and positive biofilm formation. Multilevel logistic regression analysis was performed to verify the relationship between the bacterial bioburden variable and the presence of inflammation in pressure ulcers by adjusting the total DESIGN-R ${ }^{\circledR}$ score. All statistical analyses were performed using STATA/ SE 15.0 (StataCorp LP, Collage Station, TX, USA).

\section{Ethical statement}

The study protocol was approved by the ethical committee of the Graduate School of Medicine at the University of Tokyo, and conducted in accordance with the Helsinki Declaration.

\section{Results}

From July 2014 to April 2018, 118 patients who were examined during a routine round in an interdisciplinary pressure ulcer team were assessed with category II, III, IV, or unstageable pressure ulcers. Among 458 pressure ulcer samples, 185 samples were excluded and 273 samples were ultimately included in the study analyses (Figure 1). The study participants and pressure ulcer characteristics are summarized in Table 1. The mean age of the participants was $70.1 \pm 14.1$ years, and 56 participants $(57.1 \%)$ were male. The sacrum

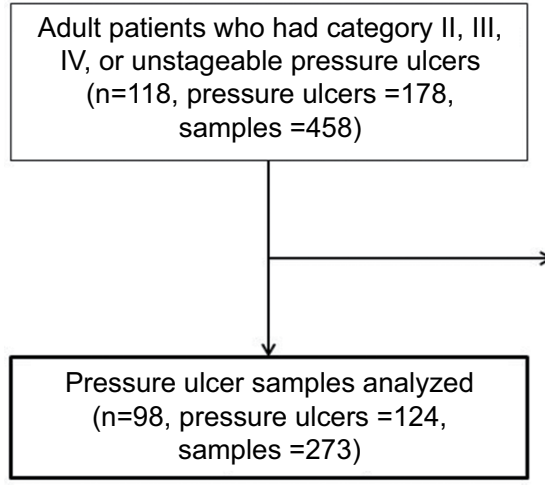

Figure I Flowchart of participants in the study
Exclusion (samples $=185$ )

- not receiving three assessments: a thermal

imaging assessment, bacterial count, and

biofilm detection (samples $=167$ )

- surface was covered completely with hard and/or thick necrotic tissue (samples $=18$ ) 
$(39 / 124,31.5 \%)$ was the most common location for pressure ulcer development. This was followed by the coccyx (22/124, $17.7 \%)$ and the greater trochanter (14/124, 11.3\%). Among the samples, 84 (30.8\%) underwent wound debridement, 171 $(62.6 \%)$ were administered with antibiotic, and $176(64.5 \%)$ were treated with silicone foam dressing. DESIGN-R ${ }^{\circledR}$ scores are summarized in Table 2 . The mean DESIGN- ${ }^{\circledR}$ total score was $13.7 \pm 8.8$, and $129(47.4 \%)$ were assessed to be $\mathrm{d} 2$, corresponding to Category II.

Results of the wound assessments using the Bacteria Counter, wound blotting, and thermography are summarized in Table 3. The mean bacterial count was $4.8 \times 10^{6} \mathrm{CFU} / \mathrm{mL}$ and the median bacterial count was $9.6 \times 10^{5} \mathrm{CFU} / \mathrm{mL}$. Biofilm formation was detected in 222 samples (81.3\%). Fifty-seven samples $(20.9 \%)$ were determined to be positive for inflammation by the thermographic assessment.

The number of samples positive and negative for inflammation with respect to bacterial count are summarized in Table 4. These results identified a significantly higher percentage of high bacterial count in samples positive for inflammation $(P=0.009)$. The results comparing presence of inflammation with respect to biofilm formation are summarized in Table 5 and show a trend for a higher percentage of samples positive for biofilm formation in the positive inflammation group $(P=0.076)$.

The results of the multilevel logistic regression analysis for evaluating the relationship between inflammation and bacterial bioburden are summarized in Table 6 . The combination of low bacterial count and positive biofilm formation was not significantly associated with wound inflammation (OR: 1.81, 95\% CI: $0.70-4.71, P=0.223$ ). However, the combination of high bacterial count and positive biofilm formation was significantly associated with wound inflammation (OR: 4.61, 95\% CI: 1.37-15.46, $P=0.013)$. Photographic examples

Table I Participants and pressure ulcer characteristics

\begin{tabular}{|l|l|}
\hline Participants (n=98) & \\
\hline Age (years) & $70.1 \pm 14.1$ \\
Sex (male) & $56(57.1)$ \\
Location (pressure ulcers =124) & $39(31.5)$ \\
Sacrum & $22(17.7)$ \\
Coccyx & $14(11.3)$ \\
Greater trochanter & $49(39.5)$ \\
Others & \\
Treatment (samples =273) & $84(30.8)$ \\
Debridement & $171(62.6)$ \\
Antiseptic & $176(64.5)$ \\
Silicone form &
\end{tabular}

Notes: Mean $\pm S D$, or number of participants, pressure ulcers, or samples (\%).
Table 2 DESIGN-R ${ }^{\circledR}$ scores of samples $(n=272)$

\begin{tabular}{|c|c|}
\hline Depth & \\
\hline $\mathrm{d} 2$ & $129(47.4)$ \\
\hline D3 & $51(18.8)$ \\
\hline D4 & $3(1.1)$ \\
\hline D5 & $2(0.7)$ \\
\hline DU & $87(32.0)$ \\
\hline \multicolumn{2}{|l|}{ Exudate } \\
\hline $\mathrm{e} 0$ & $5(1.8)$ \\
\hline el & $93(34.2)$ \\
\hline e3 & $148(54.4)$ \\
\hline E6 & $26(9.6)$ \\
\hline \multicolumn{2}{|l|}{ Size } \\
\hline s3 & $138(50.7)$ \\
\hline s6 & $72(26.5)$ \\
\hline s8 & $44(16.2)$ \\
\hline s9 & $13(4.8)$ \\
\hline$s 12$ & $3(1.1)$ \\
\hline SI5 & $2(0.7)$ \\
\hline \multicolumn{2}{|c|}{ Inflammation/infection } \\
\hline i0 & $227(83.5)$ \\
\hline il & $40(14.7)$ \\
\hline 13 & $5(1.8)$ \\
\hline \multicolumn{2}{|c|}{ Granulation tissue } \\
\hline g0 & $140(51.5)$ \\
\hline gl & $9(3.3)$ \\
\hline g3 & $16(5.9)$ \\
\hline G4 & $21(7.7)$ \\
\hline G5 & $38(14.0)$ \\
\hline G6 & $48(17.6)$ \\
\hline \multicolumn{2}{|c|}{ Necrotic tissue } \\
\hline no & $94(34.6)$ \\
\hline N3 & $170(62.5)$ \\
\hline N6 & $8(2.9)$ \\
\hline \multicolumn{2}{|l|}{ Pocket } \\
\hline $\mathrm{p} 0$ & $242(89.0)$ \\
\hline P6 & $2(0.7)$ \\
\hline P9 & II (4.0) \\
\hline $\mathrm{P} / 2$ & $9(3.3)$ \\
\hline P24 & $8(2.9)$ \\
\hline Total score & $13.7 \pm 8.8$ \\
\hline
\end{tabular}

Note: Mean $\pm S D$, or $n(\%)$, one sample was not evaluated using DESIGN-R ${ }^{\circledast}$. Abbreviation: DU, unstageable pressure ulcers.

Table 3 Assessment results of bacterial bioburden and inflammation

\begin{tabular}{|l|l|}
\hline Bacterial count (CFU/mL) & \\
\hline$<10^{5}$ & $72(26.4)$ \\
$\geq 10^{5}$ & $73(26.7)$ \\
$\geq 10^{6}$ & $97(35.5)$ \\
$\geq 10^{7}$ & $31(11.4)$ \\
Biofilm & \\
$\quad$ Positive & $222(81.3)$ \\
$\quad$ Negative & $51(18.7)$ \\
Wound inflammation (thermography) & \\
Positive & $57(20.9)$ \\
Negative & $216(79.1)$ \\
\hline
\end{tabular}

Note: $\mathrm{n}(\%)$.

Abbreviation: $\mathrm{CFU}$, colony forming unit. 
Table 4 Proportion of the pressure ulcers that were high and low bacterial counts for those with and without the inflammation detected by thermography

\begin{tabular}{|l|l|l|l|l|}
\hline \multicolumn{2}{|l|}{ Inflammation } & & \\
\hline Bacterial count & Negative (\%) & Positive (\%) & Total no. (\%) \\
\hline Low bacterial count & $197(91.2)$ & $45(79.0)$ & $242(88.6)$ & P-value \\
High bacterial count & $19(8.8)$ & $12(21.1)$ & $31(11.4)$ & 0.009 \\
Total & $216(100.0)$ & $57(100.0)$ & $273(100.0)$ & \\
\hline
\end{tabular}

Note: Low: $<1.0 \times 10^{7} \mathrm{CFU} / \mathrm{mL}$; high: $\geq 1.0 \times 10^{7} \mathrm{CFU} / \mathrm{mL}$

Abbreviation: $\mathrm{CFU}$, colony forming unit.

Table 5 Proportion of the pressure ulcers that were positive and negative for biofilm formation for those with and without the inflammation detected by thermography

\begin{tabular}{|l|l|l|l|l|}
\hline & \multicolumn{2}{|l|}{ Inflammation } & & \\
\hline Biofilm & Negative (\%) & Positive (\%) & Total no. (\%) & P-value \\
\hline Negative & $45(20.8)$ & $6(10.5)$ & $5 I(18.7)$ & 0.076 \\
Positive & $171(79.2)$ & $51(89.5)$ & $222(81.3)$ & \\
Total & $216(100.0)$ & $57(100.0)$ & $273(100.0)$ & \\
\hline
\end{tabular}

Table 6 Multilevel logistic regression analysis for evaluating the relationship between the inflammation detected by thermography and the assessment of bacterial bioburden combining bacterial count and biofilm formation

\begin{tabular}{|l|l|l|}
\hline & OR (95\% Cl) & P-value \\
\hline $\begin{array}{l}\text { Bacterial bioburden } \\
\text { Negative biofilm } \\
\text { Low bacterial count } \\
\text { and positive biofilm } \\
\text { High bacterial count } \\
\text { and positive biofilm }\end{array}$ & 1.00 & \\
Total DESIGN-R ${ }^{\circledR}$ score & $1.81(0.70-4.71)$ & 0.223 \\
\hline
\end{tabular}

of gross appearance and results of wound assessment are shown in Figure 2.

\section{Discussion}

This study assessed the relationship between bacterial bioburden of pressure ulcers, measured by both bacterial count and biofilm formation, and the presence of inflammation in patients. We found that the combination of high bacterial count and positive biofilm formation was significantly associated with the presence of wound inflammation. A previous study reported that wound cleansing promotes wound healing due to the resulting decrease in bacterial count. ${ }^{15,16}$ Moreover, positive biofilm formation can predict increased slough development in pressure ulcers. ${ }^{11}$ Thus, evaluating the bacterial bioburden by both bacterial count and pathogenicity is important. However, no study has investigated the relation- ship between the signs and/or symptoms of the wound and an assessment of bacterial bioburden based on both bacterial count and pathogenicity. Our results suggest that assessing bacterial bioburden by combining bacterial count and biofilm formation may be useful for wound management.

The combination of high bacterial count and positive biofilm formation was significantly associated with the presence of wound inflammation detected by thermography. In cases where biofilm formation is present and bacterial count is high, the biofilm is likely to mature and release planktonic bacteria. ${ }^{17}$ This situation is likely to have the greatest impact on the wound; therefore, this corresponds well with our results regarding presence of inflammation. In addition, biofilm does not release planktonic bacteria when the bacterial count is low, agreeing with our results that this situation is not significantly associated with wound inflammation. When biofilm is detected, it is advised that it should be eliminated from the wound by debridement, in addition to the basic care for controlling bacterial count (ie, wound cleansing). Moreover, when bacterial count is high, health care workers are advised to use an antiseptic to inhibit bacterial growth. The amount of time required to assess the bacterial count and biofilm formation are 1 minute and 2 minutes, respectively. Therefore, the methods used in the present study for evaluating bacterial bioburden are useful in daily wound assessment at bedside and can help to classify the type of wound care according to the bacterial bioburden.

In the present study, we evaluated inflammation through thermography. We suggested several reasons why ther- 


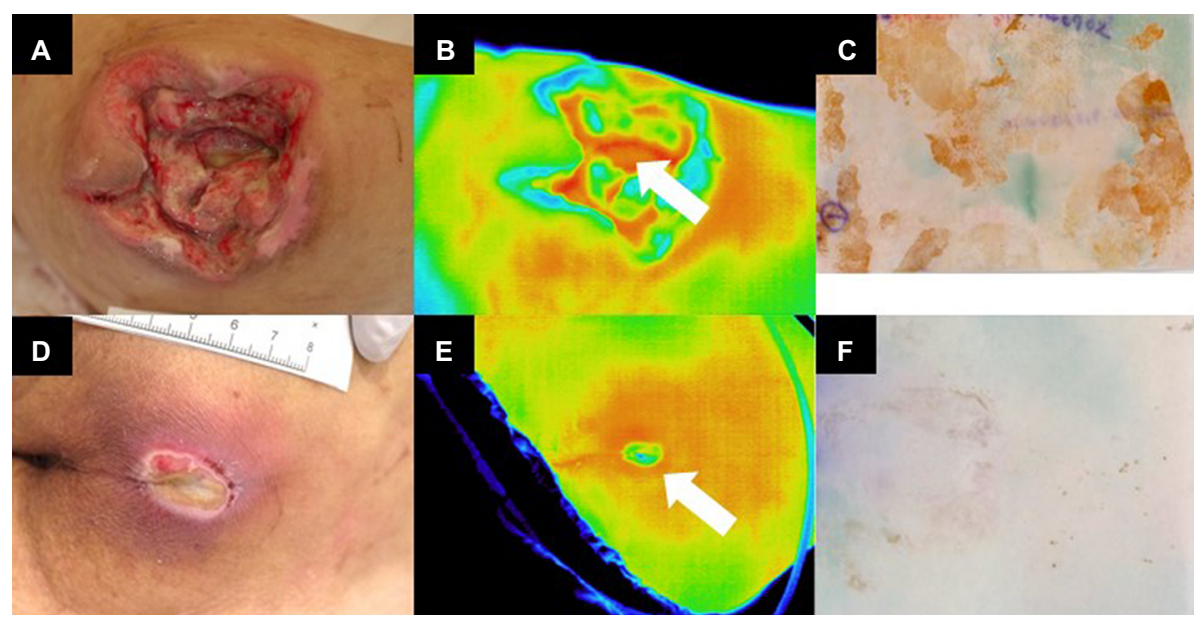

Figure 2 Representative cases for high bacterial count with positive biofilm formation and low bacterial count with negative biofilm cases.

Notes: $(\mathbf{A}-\mathbf{C})$ An 83-year-old female with a D4 pressure ulcer on her greater trochanter region. Bacterial count was $1.2 \times 10^{7} \mathrm{CFU} / \mathrm{mL}(\mathbf{A})$. The wound bed temperature was higher than the periwound skin temperature (B, white arrow); thus, this thermographic image is classified to be positive for inflammation. This wound was evaluated to be positive for biofilm formation because a signal was clearly seen on the nitrocellulose membrane (C). (D-F) A 66-year-old male with DU pressure ulcer on his sacrum region. Bacterial count was $1.0 \times 10^{5} \mathrm{CFU} / \mathrm{mL}$ (D). The wound bed temperature was lower than the periwound skin temperature (E, white arrow); therefore, inflammation was negative. No signal was observed on the nitrocellulose membrane (F); thus, biofilm formation was negative.

Abbreviations: CFU, colony forming unit; DU, unstageable pressure ulcers.

mographic assessment can be used as a relevant clinical outcome. First, excessive inflammation is an important outcome in wound healing. Second, in the case of critical colonization, the presence or absence of inflammation cannot be determined macroscopically. Third, one study reported that using thermography to detect inflammation can be a useful predictor of wound healing. ${ }^{12}$ Lastly, we excluded pressure ulcers covered by black eschar, which would have made precise thermographic measurements difficult. ${ }^{12}$ Therefore, investigating the relationship between bacterial bioburden and excessive inflammation detected by thermography is clinically valid.

The present study has several limitations. Since this study employed a cross-sectional observational design, we cannot conclude a causal relationship between bacterial bioburden and wound inflammation. Further longitudinal research involving a larger subset of patients with pressure ulcers is required to evaluate the relationship between bacterial bioburden and wound healing. The data used in this study were from a university hospital, and caution should be used when applying our findings to patients in other care settings. We assessed bacterial bioburden according to bacterial count and biofilm formation parameters. However, the specific bacteria that colonize wounds or form biofilms were not identified by the method used in this study. Recent research using molecular biological techniques has reported the relationship between poor wound healing and the transition of composition of the bacterial community. ${ }^{18}$ Therefore, in the future, it will be important to evaluate bacterial bioburden from not only the presence of bacteria, but also the composition of the microbiota.

\section{Conclusion}

Our results confirm that the combination of high bacterial count and positive biofilm formation increases the risk of wound inflammation. Our study also suggests that combining the use of a Bacteria Counter and wound blotting allows clinicians to more accurately evaluate the bacterial bioburden of the wound, which contributes to the application of appropriate wound care.

\section{Consent for publication}

The study protocol was approved by the local ethical committee, who deemed that written, informed consent was waived. Verbal consent was obtained for the use of photographs.

\section{Acknowledgments}

The authors would like to thank all patients and clinical staff for their cooperation in this study. This work was supported by JSPS KAKENHI grant number 17H04455. Competing interests: the present study was performed in collaborative research with Saraya Co. Ltd. (Tokyo, Japan). HS was offered alcian blue and its destaining solution by Saraya Co. Ltd.

\section{Author contributions}

$\mathrm{MK}$ and GN designed the study, performed statistical analyses and wrote the manuscript. MK, GN, AK, Y Mugita, and Y Mori conducted the investigation. All authors contributed 
to editing the manuscript. HS is the guarantor of this work and take full responsibility for the integrity and accuracy of the data. All authors contributed to data analysis, drafting or revising the article, gave final approval of the version to be published, and agree to be accountable for all aspects of the work.

\section{Disclosure}

The authors report no conflicts of interest in this work.

\section{References}

1. Khor HM, Tan J, Saedon NI, et al. Determinants of mortality among older adults with pressure ulcers. Arch Gerontol Geriatr. 2014;59(3):536-541.

2. Braga IA, Pirett CC, Ribas RM, Gontijo Filho PP, Diogo Filho A. Bacterial colonization of pressure ulcers: assessment of risk for bloodstream infection and impact on patient outcomes. $J$ Hosp Infect. 2013;83(4):314-320.

3. National Pressure Ulcer Advisory Panel, European Pressure Ulcer Advisory Panel and Pan Pacific Pressure Injury Alliance. Prevention and Treatment of Pressure Ulcers: Clinical Practice Guideline. 2nd ed. Haesler E, editor. Perth, WA: Cambridge Media; 2014.

4. Wolcott RD, Hanson JD, Rees EJ, et al. Analysis of the chronic wound microbiota of 2,963 patients by $16 \mathrm{~S}$ rDNA pyrosequencing. Wound Repair Regen. 2016;24(1):163-174.

5. Gardner SE, Hillis SL, Heilmann K, Segre JA, Grice EA. The neuropathic diabetic foot ulcer microbiome is associated with clinical factors. Diabetes. 2013;62(3):923-930.

6. Malone M, Johani K, Jensen SO, et al. Next generation DNA sequencing of tissues from infected diabetic foot ulcers. EBioMedicine. 2017;21:142-149.
7. Hamada R, Suehiro J, Nakano M, Kikutani T, Konishi K. Development of rapid oral bacteria detection apparatus based on dielectrophoretic impedance measurement method. IET Nanobiotechnol. 2011;5(2):25-31.

8. Nakagami G, Yoshida S, Matsumoto M, et al. A new objective evaluation method for PU cleansing using a rapid bacteria counting system. J Wound Care. 2013;22(5):278-281.

9. Nakagami G, Mori M, Yoshida M, et al. Inter-rater and intra-rater reliability outcomes of a rapid bacteria counting system with pressure ulcer samples. J Wound Care. 2017;26(Supp 2):S27-S31.

10. Wolcott RD, Rhoads DD. A study of biofilm-based wound management in subjects with critical limb ischaemia. $J$ Wound Care. 2008;17(4):145-155.

11. Nakagami G, Schultz G, Gibson DJ, et al. Biofilm detection by wound blotting can predict slough development in pressure ulcers: a prospective observational study. Wound Repair Regen. 2017;25(1):131-138.

12. Nakagami G, Sanada H, Iizaka S, et al. Predicting delayed pressure ulcer healing using thermography: a prospective cohort study. JWound Care. 2010;19(11):465-470.

13. Matsui Y, Furue M, Sanada H, et al. Development of the DESIGN-R with an observational study: an absolute evaluation tool for monitoring pressure ulcer wound healing. Wound Repair Regen. 2011;19(3):309-315.

14. Sanada H, Moriguchi T, Miyachi Y, et al. Reliability and validity of DESIGN, a tool that classifies pressure ulcer severity and monitors healing. J Wound Care. 2004;13(1):13-18.

15. Konya C, Sanada H, Sugama J, et al. Skin debris and micro-organisms on the periwound skin of pressure ulcers and the influence of periwound cleansing on microbial flora. Ostomy Wound Manage. 2005;51(1):50-59.

16. Konya C, Sanada H, Sugama J, Okuwa M, Kitagawa A. Does the use of a cleanser on skin surrounding pressure ulcers in older people promote healing? J Wound Care. 2005;14(4):169-171.

17. Omar A, Wright J, Schultz G, Burrell R, Nadworny P. Microbial biofilms and chronic wounds. Microorganisms. 2017;5(1):9.

18. Loesche M, Gardner SE, Kalan L, et al. Temporal stability in chronic wound microbiota is associated with poor healing. J Invest Dermatol. 2017;137(1):237-244.
Chronic Wound Care Management and Research

\section{Publish your work in this journal}

Chronic Wound Care Management and Research is an international, peer reviewed, open access, online journal publishing original research, reviews, editorials, and commentaries on the causes and management of chronic wounds and the major issues related to chronic wound management. Topics also include chronic wounds as comorbidities to other

\section{Dovepress}

conditions, patient adherence to therapy, and the economic burden of chronic wounds. The manuscript management system is completely online and includes a very quick and fair peer review system, which is all easy to use. Visit http://www.dovepress.com/testimonials.php to read real quotes from published authors. 